\title{
PEMANFAATAN TEKNOLOGI DATA MINING DALAM MENENTUKAN EFEKTIFITAS PENYEBARAN BROSUR
}

\author{
Fajar Ardanu'), Hidayatulah Himawan ${ }^{2)}$, Dessyanto Boedi $\mathbf{P}^{3)}$ \\ Program Studi Teknik Informatika UPN "Veteran" Yogyakarta \\ Jl. Babarsari 2, Tambakbayan, Yogyakarta, 55281 \\ e-mail : if.iwan@upnyk.ac.id
}

\begin{abstract}
During this time many organizations or companies that perform marketing products using brochures. The spread of this brochure done anywhere and at any time regardless of the amount. The purpose of this course the distribution of brochures to attract people to buy a product from a company or organization. However, companies often do not pay attention to when the time is right to make the distribution of brochures where and who are the target consumers of the company in accordance with the products on offer, so it designed a system with data mining technology that can be used to determine the distribution of brochures schedule, location deployment brochures and anyone taget consumer. The methodology used in the making of this application is a waterfall methodology. While the software used in building this application is c45 algorithm and its implementation in the form of desktop built using Visual Basic 6.0 and SQL Server 2000. Application of data mining technology using c45 algorithm gives information in determining the effectiveness of the distribution of brochures. This application also comes with a data member and employee information .
\end{abstract}

Keywords : brochure, data mining, aplication, algoritma c45

Selama ini banyak organisasi atau perusahaan yang melakukan pemasaran produk dengan menggunakan brosur. Penyebaran brosur ini dilakukan setiap saat dimana saja dan berapapun jumlahnya. Tujuan dari penyebaran brosur ini tentu saja untuk menarik minat masyarakat agar membeli produk dari perusahaan atau organisasi tersebut. Namun, perusahaan kadang tidak memperhatikan kapan waktunya yang tepat untuk melakukan penyebaran brosur dimana dan siapa saja yang menjadi target konsumen pada perusahaan tersebut sesuai dengan produk yang ditawarkan, sehingga dirancang suatu sistem dengan teknologi data mining yang dapat digunakan untuk menentukan jadwal penyebaran brosur, lokasi penyebaran brosur dan siapa saja taget konsumen. Metodologi yang digunakan dalam pembuatan aplikasi ini adalah metodologi waterfall. Sedangkan perangkat lunak (software) yang digunakan dalam membangun aplikasi ini adalah algoritma c45 dan implementasinya dalam bentuk dekstop yang dibangun menggunakan Visual Basic 6.0 dan SQL Server 2000. Aplikasi teknologi data mining menggunakan algoritma c45 memberi informasi dalam menentukan efektifitas penyebaran brosur. Aplikasi ini juga dilengkapi dengan informasi data anggota dan karyawan.

Kata kunci : brosur, data mining, aplikasi, algoritma c45

\section{PENDAHULUAN}

Dengan kemajuan teknologi informasi dewasa ini, kebutuhan akan informasi yang akurat sangat dibutuhkan dalam kehidupan sehari-hari, sehingga informasi akan menjadi suatu elemen penting dalam perkembangan masyarakat saat ini dan waktu mendatang. Namun kebutuhan informasi yang tinggi kadang tidak diimbangi dengan penyajian informasi yang memadai, sering kali informasi tersebut masih harus di gali ulang dari data yang jumlahnya sangat besar. Kemampuan teknologi informasi untuk mengumpulkan dan menyimpan berbagai tipe data jauh meninggalkan kemampuan untuk menganalisis, meringkas dan mengekstrak pengetahuan dari data. Metode tradisional untuk menganalisis data yang ada, tidak dapat menangani data dalam jumlah besar.

Pemanfaatan data yang ada di dalam sistem informasi untuk menunjang kegiatan pengambilan keputusan, tidak cukup hanya mengandalkan data operasional saja, diperlukan 
suatu analisis data untuk menggali potensi-potensi informasi yang ada. Para pengambil keputusan berusaha untuk memanfaatkan gudang data yang sudah dimiliki untuk menggali informasi yang berguna membantu mengambil keputusan, hal ini mendorong munculnya cabang ilmu baru untuk mengatasi masalah penggalian informasi atau pola yang penting atau menarik dari data dalam jumlah besar, yang disebut dengan data mining. Penggunaan teknik data mining diharapkan dapat memberikan pengetahuan-pengetahuan yang sebelumnya tersembunyi di dalam gudang data sehingga menjadi informasi yang berharga.

Perusahaan saat ini dituntut untuk memiliki keunggulan bersaing dengan memanfaatkan semua sumber daya yang dimiliki. Selain sumber daya sarana, prasarana, dan manusia, sistem informasi adalah salah satu sumber daya yang dapat digunakan untuk meningkatkan keunggulan bersaing.Selama ini banyak organisasi atau perusahaan yang menggunakan brosur untuk memberikan informasi kepada masyarakat, seperti halnya pada perusahaan Astarinet. Penyebaran brosur ini dilakukan setiap saat dimana saja dan berapapun jumlahnya. Tujuan dari penyebaran brosur ini tentu saja untuk menarik minat masyarakat agar membeli produk dari perusahaan atau organisasi tersebut.Namun, perusahaan kadang tidak memperhatikan kapan waktunya yang tepat untuk melakukan penyebaran brosur dimana dan siapa saja yang menjadi target konsumen padaperusahaan tersebut sesuai dengan produk yang ditawarkan.

Dari permasalahan di atas disusunlahsuatu sistem dengan teknologi data mining yang dapat digunakan untuk menentukan jadwal penyebaran brosur, lokasi penyebaran brosur dan siapa saja target konsumen.Aplikasi pemanfaatan teknologi data mininginimenggunakan algoritma C45 untuk menentukan efektifitas penyebaran brosur yang dapat digunakan untuk memberi masukan/saran kepada perusahaan untuk menentukan tingkat keefektifan dimana saja brosur disebarkan, kapan waktu yang tepat dan kepada siapa saja target utama dari penyebaran brosur.

\section{METODE PENELITIAN}

Metodologi yang dilakukan dalam pengembangan sistem ini menggunakan perpaduan antara metode analisa yang bersifat kualitatif dan metode Waterfall (Pressman, 2002) pada tahap implementasi sistem. Adapun tahapan dalam metode Waterfall adalah :

1. Analisis dan perancangan sistem (System Engineering)

2. Analisis kebutuhan perangkat lunak (Analysis)

3. Perancangan (Design)

4. Pengkodean (Coding)

5. Pengujian (Testing)

6. Pemeliharaan (Maintenance)

Pada penelitian ini metodologi pengembangan sistem yang digunakan hanya sampai pada tahap Pengujian (Testing).

\section{ANALISA KEBUTUHAN SISTEM DAN PERANCANGAN}

Brosur adalah salah satu cara mempromosikan suatu barang atau jasa yang biasanya digunakan oleh perusahaan. Brosur juga biasa digunakan untuk meningkatkan pemasaran barang atau jasa tertentu yang ditawarkan oleh perusahaan. Seperti halnya pada Perusahaan Astarinet, brosur digunakan sebagai sarana peningkatan pemasaran sekaligus pemberian kesempatan kepada orang lain untuk menjadi member dan memiliki usaha sendiri. Namun, Perusahaan Astarinet merasa proses peningkatan pemasaran belum dikatakan efektif.

Di saat teknologi informasi mulai berkembang pesat dan dalam dunia bisnis saat ini, baik pada perusahaan kecil maupun perusahaan besar, mulai menyadari pentingnya suatu teknologi yang dapat membantu mengembangkan usahanya. Kebutuhan informasi yang cepat dan tepat menjadi sangat penting untuk mengefisiensikan waktu. Untuk mengatasi permasalahan dalam efektivitas peningkatan pemasaran, diperlukan suatu alat analisis bagi perusahaan untuk mengetahui efektifitas penyebaran brosur.Alat analisis tersebut berupa sebuah aplikasi penunjang keputusan berbasis komputer yang mengimplementasikan algoritma klasifikasi data mining.Dengan ketersediaan data anggota, data mining dapat menggali informasi yang terkubur 
dari kumpulan data anggota tersebut. Aplikasi ini dapat digunakan untukmenganalisis efektifitas penyebaran brosur berdasarkan data anggota yang telah terkumpul sebelumnya.

Data yang akan digunakan dalam membentuk pohon keputusan untuk mengetahui efektifitas penyebaran brosur adalah data anggota Perusahaan Astarinet pada tahun 2011. Data anggota tersebut selanjutnya akan dilakukan pra-proses untuk menghasilkan data kasus yang siap untuk dibentuk menjadi sebuah pohon keputusan.

\section{Data Flow Diagram (DFD)}

Data Flow Diagram (DFD) merupakan salah satu metode untuk menggambarkan jalannya aliran data dalam sistem. DFD level 0, merupakan DFD tingkat awal atau disebut juga diagram konteks. Diagram konteks adalah diagram yang menggambarkan satu lingkaran besar yang dapat mewakili seluruh proses yang terdapat di dalam suatu sistem. Semua entitas eksternal yang ditunjukkan pada diagram konteks berikut aliran-aliran data utama menuju dan dari sistem. DFD level 0 dapat dilihat pada gambar 1.

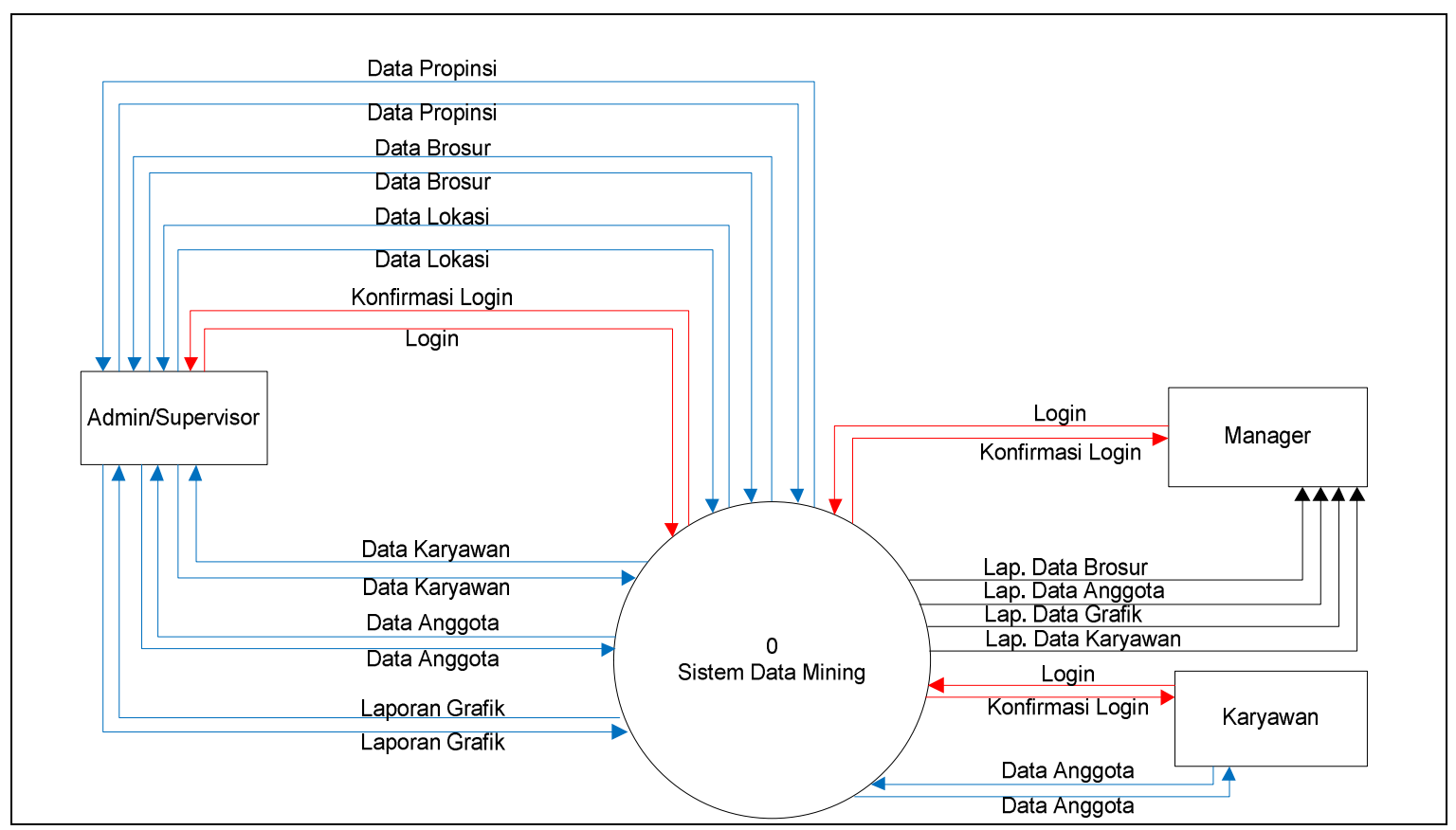

Gambar 1. DFD level 0

Admin/ Supervisor dapat melakukan login, mengolah data propinsi, data brosur, data lokasi, data karyawan, data anggota dan data grafik. Karyawan dapat melakukan login dan mengolah data anggota, sedangkan manager dapat melakukan login dan menerima laporan data brosur, laporan data anggota, laporan data grafik, dan laporan data karyawan.

\section{Flowchart}

Dalam aplikasi ini, rancangan alur program dituangkan ke dalam alur program flowchart terlebih dahulu. Alur program dalam sistem data minin menggunakan algoritma c45 ini dapat dilihat pada gambar 2 . 
Proses input data anggota

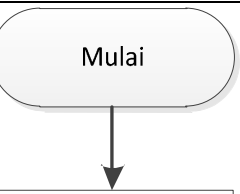

Input Data Anggota

Perhitungan dimulai dari entropi seluruh data dan masing-masing atribut data anggota, dilanjutkan perhitungan gain tiap atribut

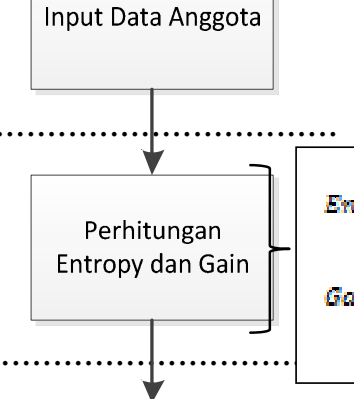

Atribut data yang memiliki nilai gain tertinggi dan memiliki nilai $\mathrm{e}=0$ dipilih sebagai node akar

\section{Penentuan Atribut} sebagai Node Akar
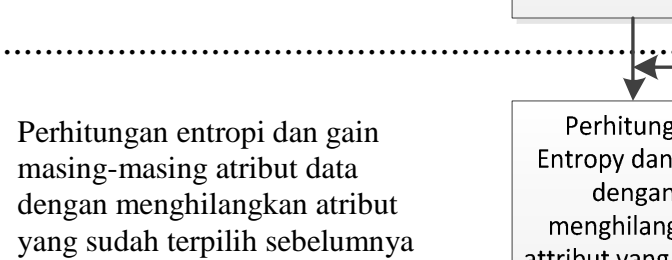

Perhitungan

Entropy dan Gain dengan

menghilangkan attribut yang sudah terpilih Entropy $(s)=\sum_{i=1}^{n}-p^{-1} \log _{n i}$ $\operatorname{Gain}(S, A)=\operatorname{Entropy}(S)-\sum_{i=1}^{n} \frac{|S|}{|S|}-\operatorname{Entropy}(S \mathrm{~S})$ terpilih sebelumnya

Atribut data yang memiliki nilai gain tertinggi dan memiliki nilai $\mathrm{e}=0$ dipilih sebagai node cabang

Cek apakah semua atribut sudah dibentuk pada pohon

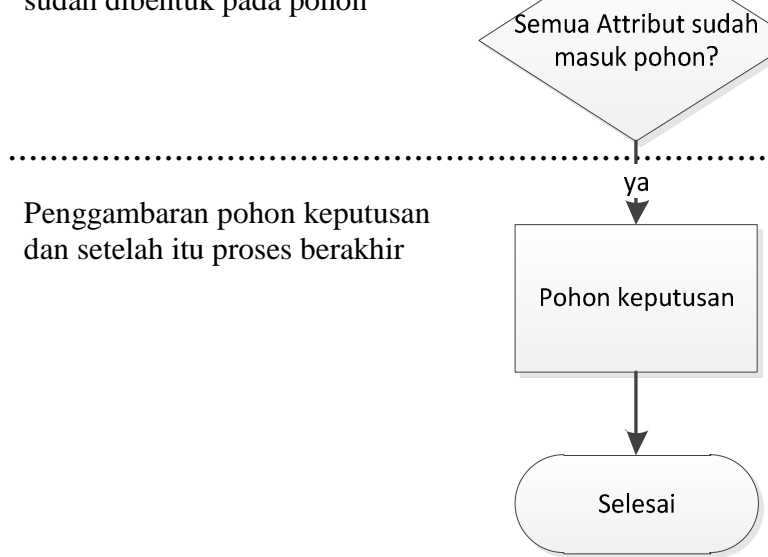

\section{Gambar 2. Flowchart}

Sistem data mining ini akan dimulai dengan menginput data anggota. Kemudian sistem akan membagi data anggota pada masing-masing atribut yaitu dimana, kapan dan siapa. Setelah itu sistem akan melakukan perhitungan nilai entropy dari seluruh data dan masingmasing atribut data. Apabila diperoleh nilai entropy $=0$ pada nilai atribut, maka itu berarti nilai atribut tersebut sudah mengklasifikasikan kasus menjadi satu keputusan. Setelah perhitungan nilai entropy selesai, maka sistem ini akan menghitung nilai gain terhadap masing-masing 
atribut data. Pada perhitungan ini akan diketahui atribut data yang memiliki nilai gain tertingggi. Setelah itu atribut data yang memiliki nilai gain tertinggi dan memiliki nilai entropy 0 dipilih sebagai node akar. Dari hasil keputusan yang diambil, sistem akan melakukan perhitungan kembali nilai entropydan nilai gain dengan menghilangkan atribut data yang sudah dipilih sebelumnya. Pada perhitungan ini, atribut data yang memiliki nilai gain tertingggi dan memiliki nilai entropy 0 dipilih sebagai node cabang.Kemudian sistem akan mengecek apakah semua atribut sudah dibentuk pada pohon, jika belum maka proses perhitungan entropy dan gain akan diulangi kembali. Jika sudah maka akan dilanjutkan ke proses berikutnya yaitu penggambaran pohon keputusan dan setelah itu proses berakhir.

\section{HASIL DAN PEMBAHASAN}

Sebelum masuk dalam halaman menu utama setiap user wajib untuk mengisi kolom nama pemakai, password dan status untuk masuk dapat mengakses ke halaman berikutnya. Tampilan login ini dilakukan oleh supervisor, manager, dan karyawan. Tampilan halaman login dapat dilihat seperti pada gambar 3 sebagai berikut :

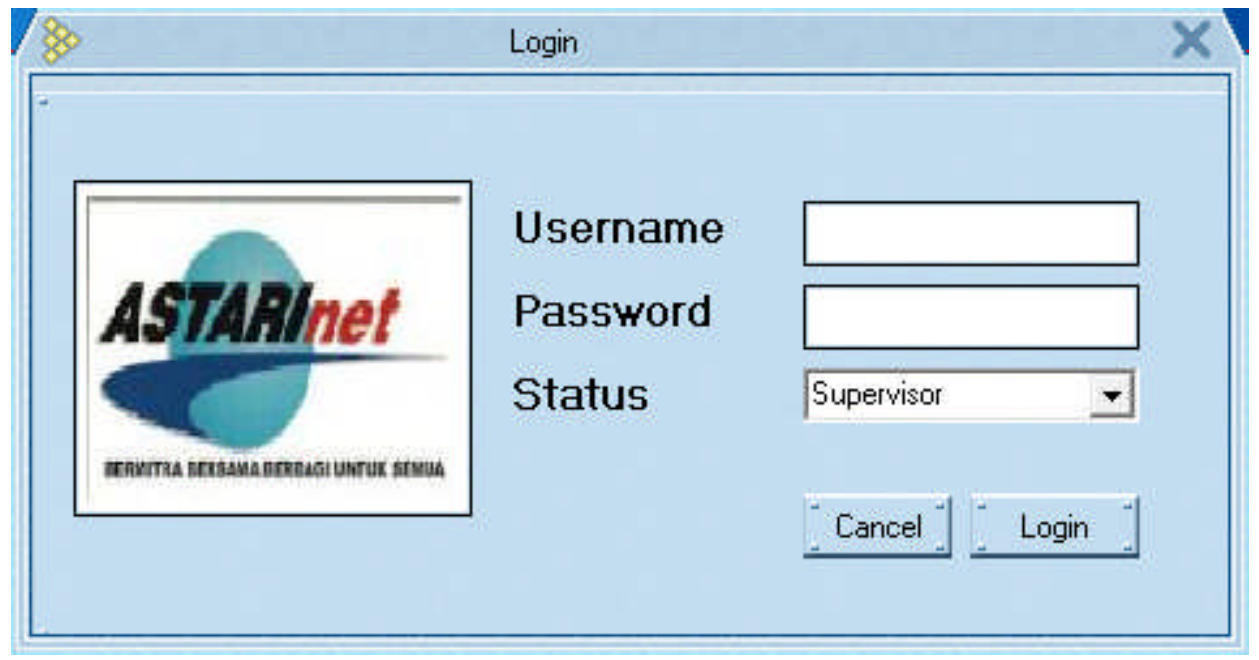

Gambar 3. Halaman Login

Adapun modul program tampilan halaman login dapat dilihat pada modul program 1, yaitu :

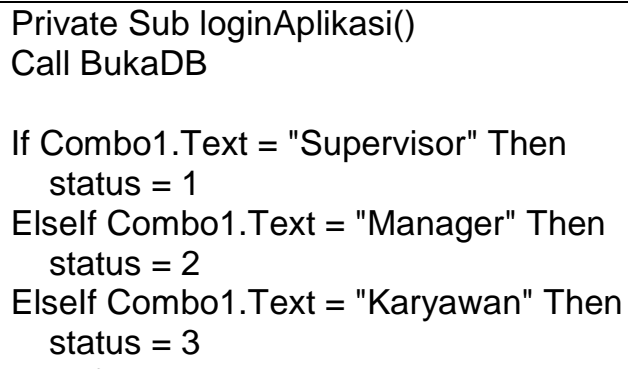

Modul Program 1. Halaman Login

Halaman Brosur

Pada halaman ini admin dapat melakukan pengolahan data brosur seperti menambah, merubah, dan menyimpan data brosur. Tampilan halaman olah data brosur seperti gambar 4 berikut. 


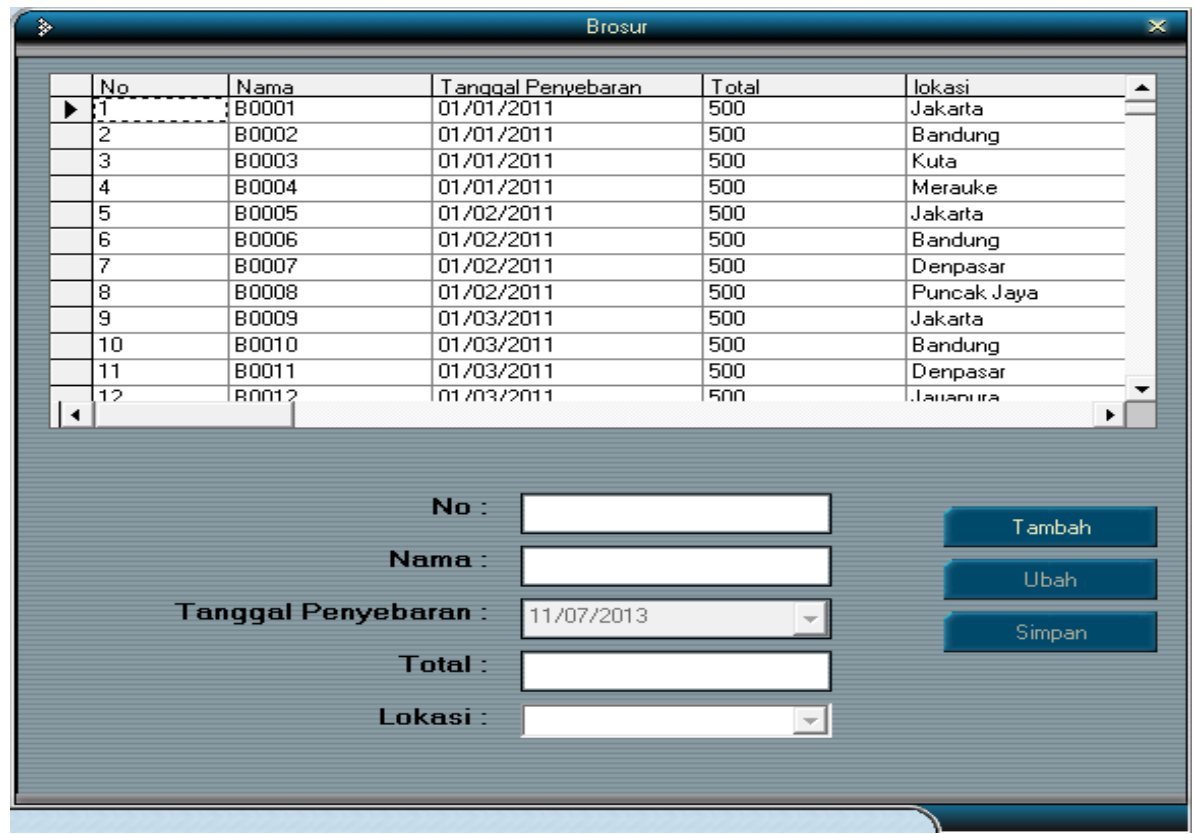

Gambar 4. Halaman Brosur

Adapun modul program tampilan halaman brosur dapat dilihat pada modul program 2, yaitu :

Private Sub DataGrid1_Click()

txtld. Text $=$ DataGrid1.Columns(0). Value

txNama.Text = DataGrid1.Columns(1).Value

DTPicker1.Value = DataGrid1.Columns(2). Value

txttotal.Text $=$ DataGrid1.Columns(3).Value

txtlokasi.Text $=$ DataGrid1.Columns(4).Value

btUbah.Enabled $=$ True

btSimpan. Enabled $=$ False

btTambah. Enabled $=$ True

fieldClose

End Sub

\section{Halaman Grafik Wilayah}

Modul Program 2. Halaman Brosur

Pada halaman ini admin dapat melihat jumlah anggota berupa grafik sesuai wilayah yaitu WIB, WITA, dan WIT.Tampilan halaman grafik seperti gambar 5 berikut.

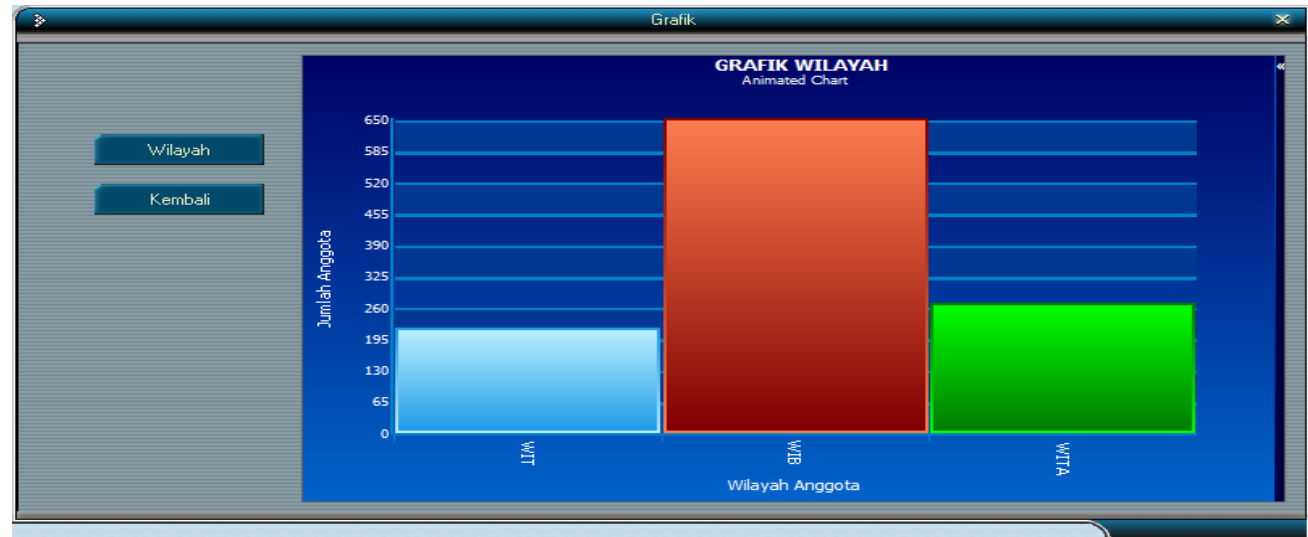

Gambar 5. Halaman Grafik Wilayah

Adapun modul program untuk halaman grafik wilayah dapat dilihat pada modul program 3. 


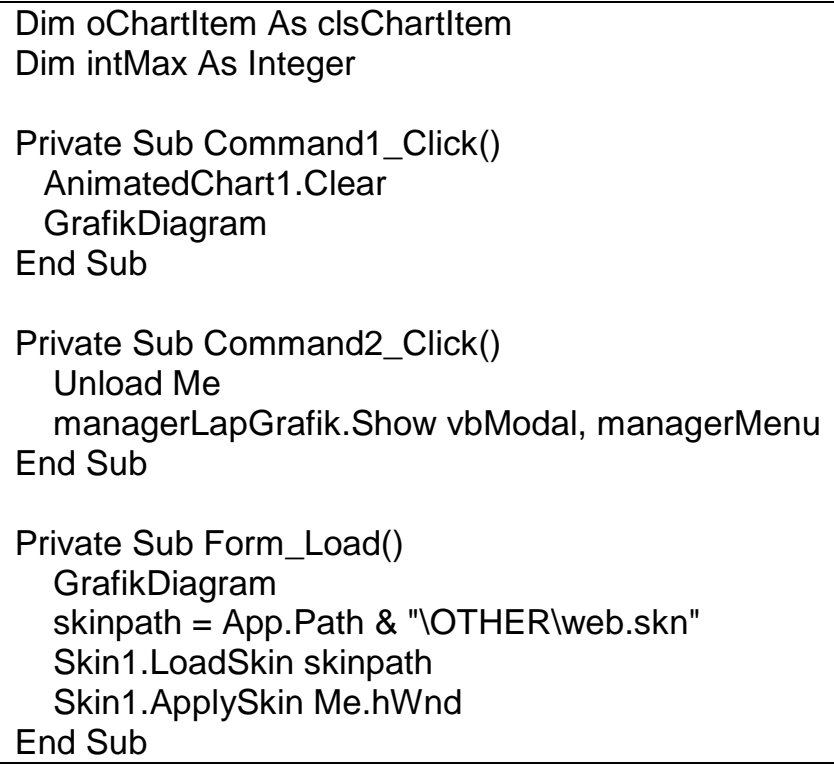

Pada halaman ini manager dapat melihat laporan data anggota yang berisi no.id, kode brosur, nama, tempat lahir, tanggal lahir, umur, jenis kelamin, tanggal masuk, kota, alamat dan nomor telepon. Tampilan halaman laporan data anggota seperti gambar 6 berikut.

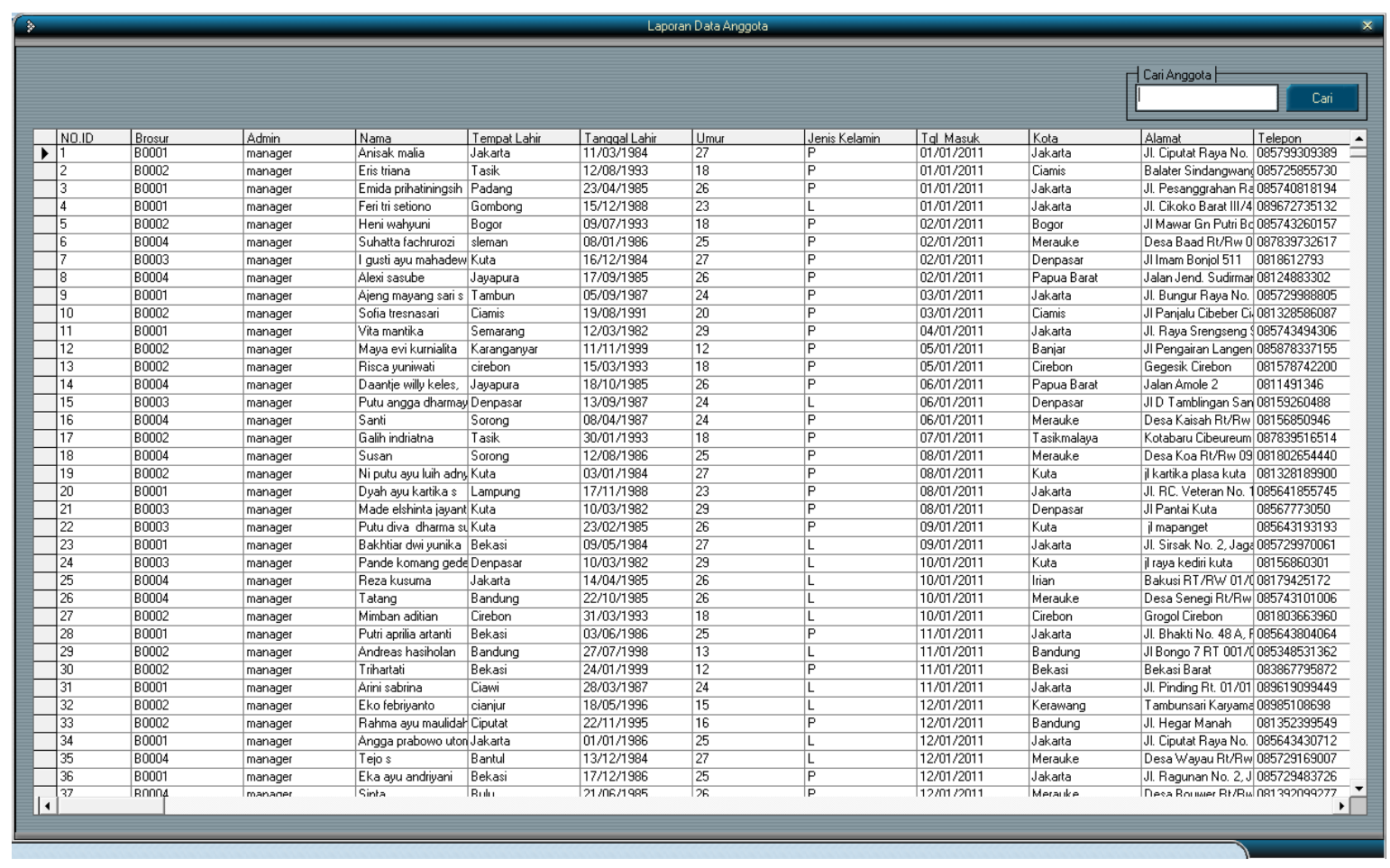

Gambar 6. Halaman Laporan Anggota

Adapun modul program halaman laporan anggot dapat dilihat pada modul program 4 di bawah ini . 


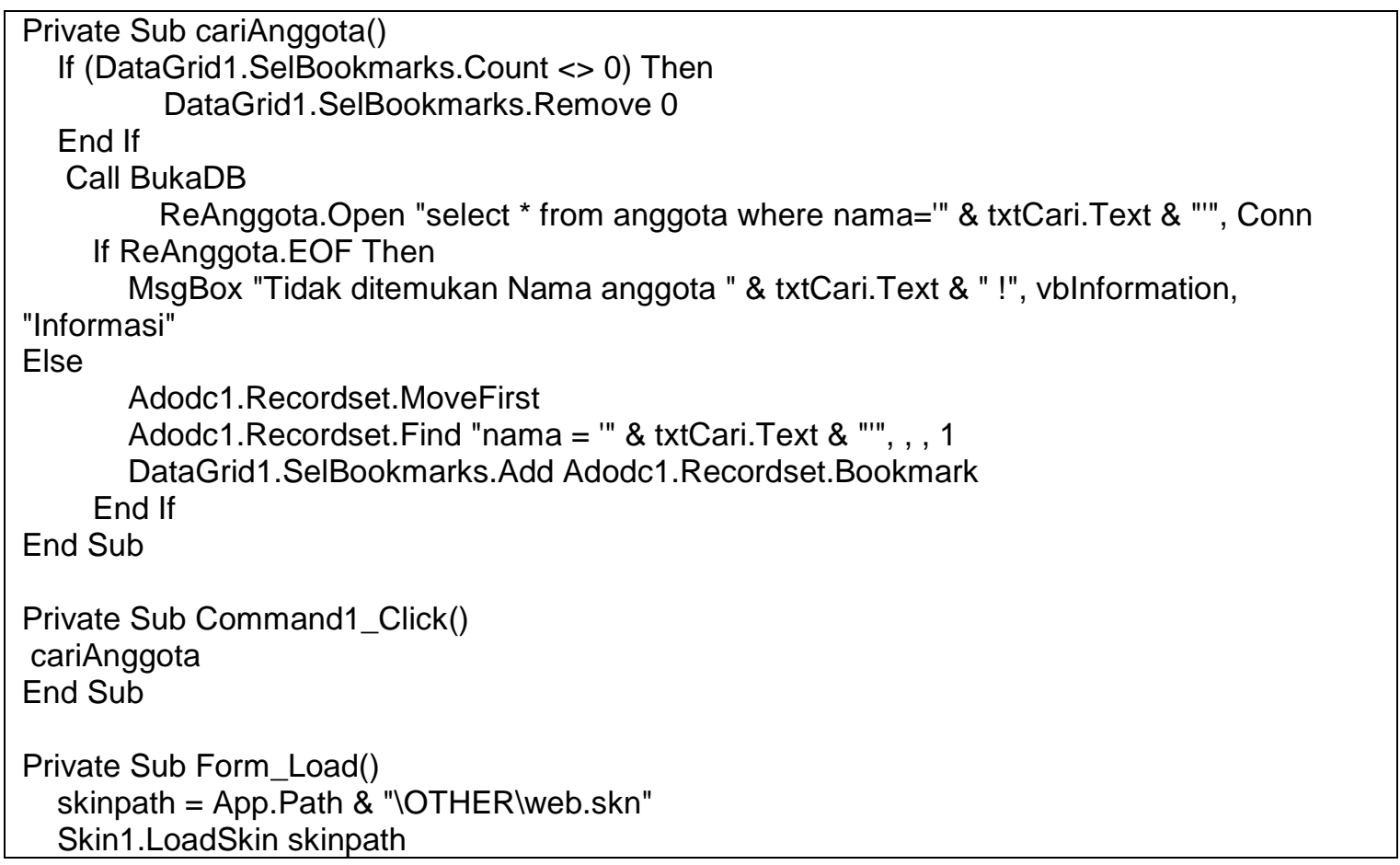

Modul Program 4. Halaman Laporan Anggota

\section{KESIMPULAN}

Dari penelitian di atas, dapat diambil kesimpulan sebagai berikut $: 1$

1. Telah dihasilkan aplikasi pemanfaatan teknologi data mining menggunakan algoritma C45 untuk menentukan efektifitas penyebaran brosur (study kasus astarinet).

2. Hasil yang ditampilkan pada pohon keputusan berdasarkan tiga klasifikasi yaitu wilayah (WIB, WITA, WIB), waktu (awal tahun, tengah tahun, akhir tahun), dan Usia (remaja, dewasa)

\section{DAFTAR PUSTAKA}

Al Fatta, Hanif. 2007. Analisis dan Perancangan Sistem Informasi untuk keunggulan Bersaing Perusahaan dan Organisasi Modern.Yogyakarta: Andi offset

Chan, Syahrial.2004. MembuatAplikasi GL dengan Power Builder 9.0 dan SQL Server 2000.Jakarta: PT. Elex Media kompetindo

Dayanti, Septi Dwi. 2011.Pengaruh Model Pembelajaran Cooperative Learning Tipe Student Team Achievement Divisions (Stad) Pada Pencapaian Kompetensi Membuat Pola Blazer Di Smk N I Sewon Bantul. Skripsi. UNY

Hartono, Jogiyanto. 2005. Analisis \& Desain Sistem Informasi Pendekatan Terstruktur Teori dan Praktek Aplikasi Bisnis. Yogyakarta: Andi offset

Indrajit, Richardus Eko.2000. Pengantar Konsep Dasar: Manajemen Sistem Informasi dan Teknologi Informasi.Jakarta: PT. Elex Media kompetindo

Kurniawan, Yahya. 2005. Kiat Praktis Menguasai Action Script 2.0 Flas MX 2004. Jakarta: PT. Elex Media kompetindo

Kusrini,danAndriKoniyo. 2007. Tuntunan praktis membangun sistem informasi akutansi dengan visual basic dan microsoft SQL server. Yogyakarta: Andi offset

Mangkolo, Hengky Alexander. 2004.Belajar Sendiri Aplikasi Database Menggunakan ADO VB6 dan SQL Server 2000. Jakarta: PT. Elex Media kompetindo

Pressman, Roger S. 2002. Rekayasa Perangkat Lunak Pendekatan Praktisi. Yogyakarta: Andi offset

Priyono, Henry. 2007. Seri Penuntun Praktis Siapa Bilang Pemograman Itu Sulit. Jakarta: PT. Elex Media kompetindo 